\section{Unusual cause of CA 19.9 elevation diagnosed by endoscopic ultrasound-guided fine needle aspiration: a retrorectal tailgut cyst}
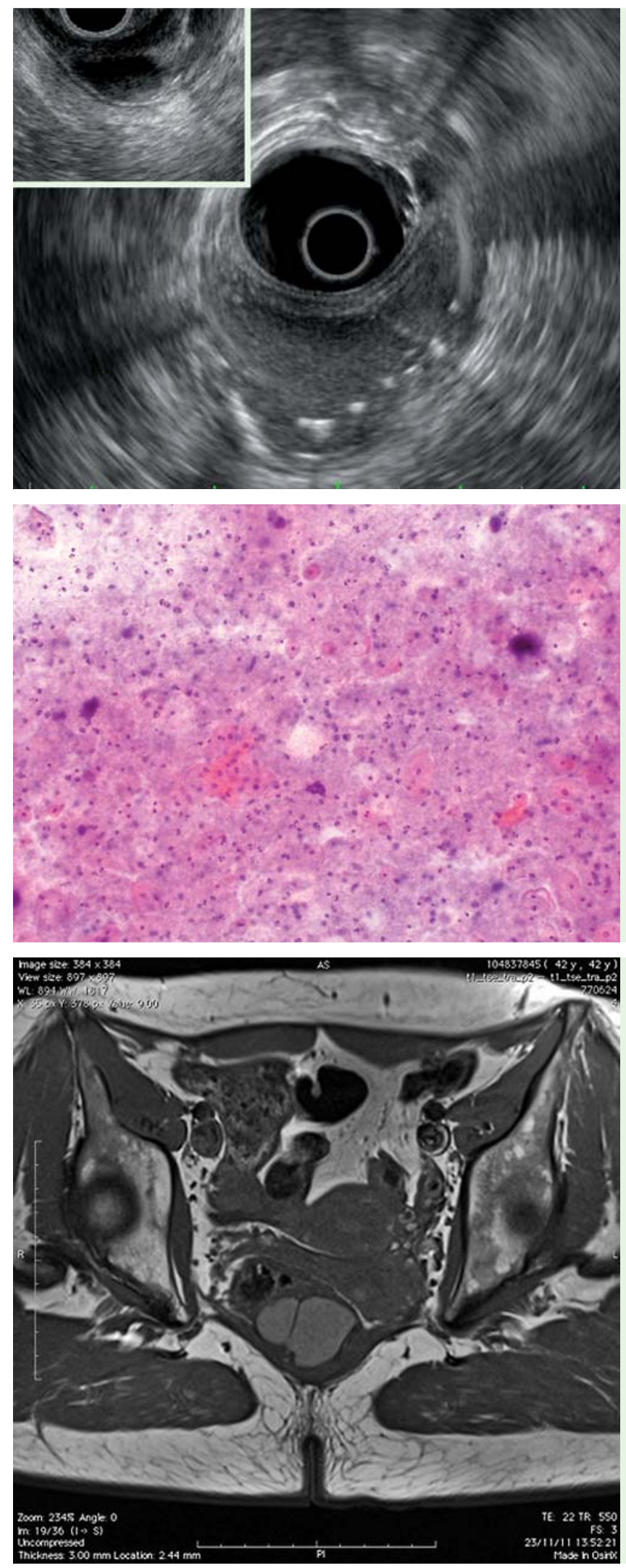

Fig. 1 Endoscopic ultrasound (EUS) image: retrorectal cystic lesion with echogenic foci. Detail: additional small cystic lesion adjacent to the anal canal, which has been described as a potential cause of recurrence.

Fig. 2 Fine needle aspiration (FNA) smears showing proteinaceous background, squamous cells without atypia, anucleated squames, microcalcifications, and debris (Papanicolaou stain, $\times 100)$.

Fig. 3 Multicystic retrorectal lesion. Several cysts with a high signal in a T1-weighted image, interspersed in a fibrous septa, reported in mucinous fluid with high protein concentration.
A 42-year-old woman underwent a magnetic resonance imaging (MRI) scan for CA 19.9 elevation, noted during a routine evaluation. Endoscopic ultrasound-guided fine needle aspiration (EUS-FNA) of a retrorectal cystic mass of unknown etiology was scheduled. A 5-cm multiseptated cystic lesion was noted ( Fig. 1). Under antibiotic prophylaxis, FNA was performed (19-gauge needle; single pass); the aspirate was thick and yellowish. Cytological examination showed squamous epithelial cells but no atypia (๑ Fig.2). In-house MRI confirmed a multicystic lesion with a hyperintense signal on T1-weighted images ( Fig. 3). The patient opted for a laparoscopic resection, which confirmed a tailgut cyst ( Fig.4), with later CA 19.9 normalization.

The human embryo possesses a true tail as an extension of the primitive gut. A retrorectal cystic hamartoma (tailgut cyst) is a rare congenital lesion representing a nonregressed tail. Usually found in asymptomatic middle-aged women, local mass effect or complications, namely malignant degeneration, have been described [1]. Ultrasound shows multilocular cystic lesions with internal echoes due to mucoid material or inflammatory debris. Surgical excision is the gold-standard treatment, with the laparoscopic approach being the most recent option [2]. There is only one report of EUS-FNA with a flexible echoendoscope [3]. Puncture should be performed when other etiologies are considered or if malignant degeneration changes management. Finally, clinicians should be aware that benign tailgut cysts are a rare cause of mild CA 19-9 elevation [4].

Endoscopy_UCTN_Code_CCL_1AF_2AH

Competing interests: None

P. Pinto-Marques ${ }^{1}$, J. Damião-Ferreira², E. Mendonça ${ }^{3}$, A. Gaspar ${ }^{4}$, M. Mafra ${ }^{3}$,

\section{F. Mateus ${ }^{1}$}

${ }^{1}$ Department of Gastroenterology, Hospital da Luz, Lisbon, Portugal

2 Department of General Surgery, Hospital da Luz, Lisbon, Portugal ${ }^{3}$ Department of Pathology, Hospital da Luz, Lisbon, Portugal

${ }^{4}$ Department of Radiology, Hospital da Luz, Lisbon, Portugal 


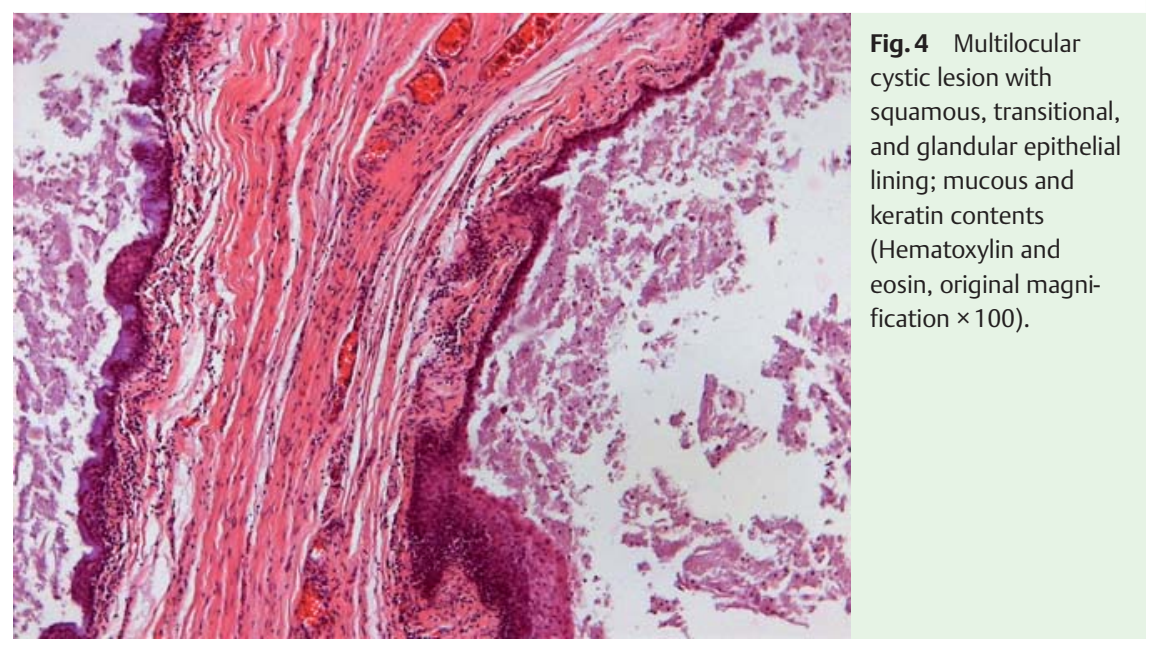

\section{References}

1 Hjermstad B, Helwig E. Tailgut cysts. Report of 53 cases. Am J Clin Pathol 1988; 89: 139-147

2 Lu N, Tseng M. Laparoscopic management of tailgut cyst: case report and review of the literature. J Minim Invasive Gynecol 2010; 17: $802-804$

3 Hall D, Pu R, Pang Y. Diagnosis of foregut and tailgut cysts by endosonographically guided fine-needle aspiration. Diagn Cytopathol 2007; 35: 43-46

4 Garcia-Donas J, Rodriguez N, Jara C et al. Retrorectal cystic hamartoma as a benign cause of CA 19.9 elevation. J Clin Oncol 2007; 25: $4012-4014$

\section{Bibliography}

DOI http://dx.doi.org/

10.1055/s-0032-1309757

Endoscopy 2012; 44: E248-E249

(c) Georg Thieme Verlag KG

Stuttgart · New York

ISSN 0013-726X

\section{Corresponding author}

P. Pinto-Marques, MD, MSc

Department of Gastroenterology Hospital da Luz

Avenida Lusiada 100

Lisbon 1500-650

Portugal

Fax: +351-21-7104409

pmarques@hospitaldaluz.pt 